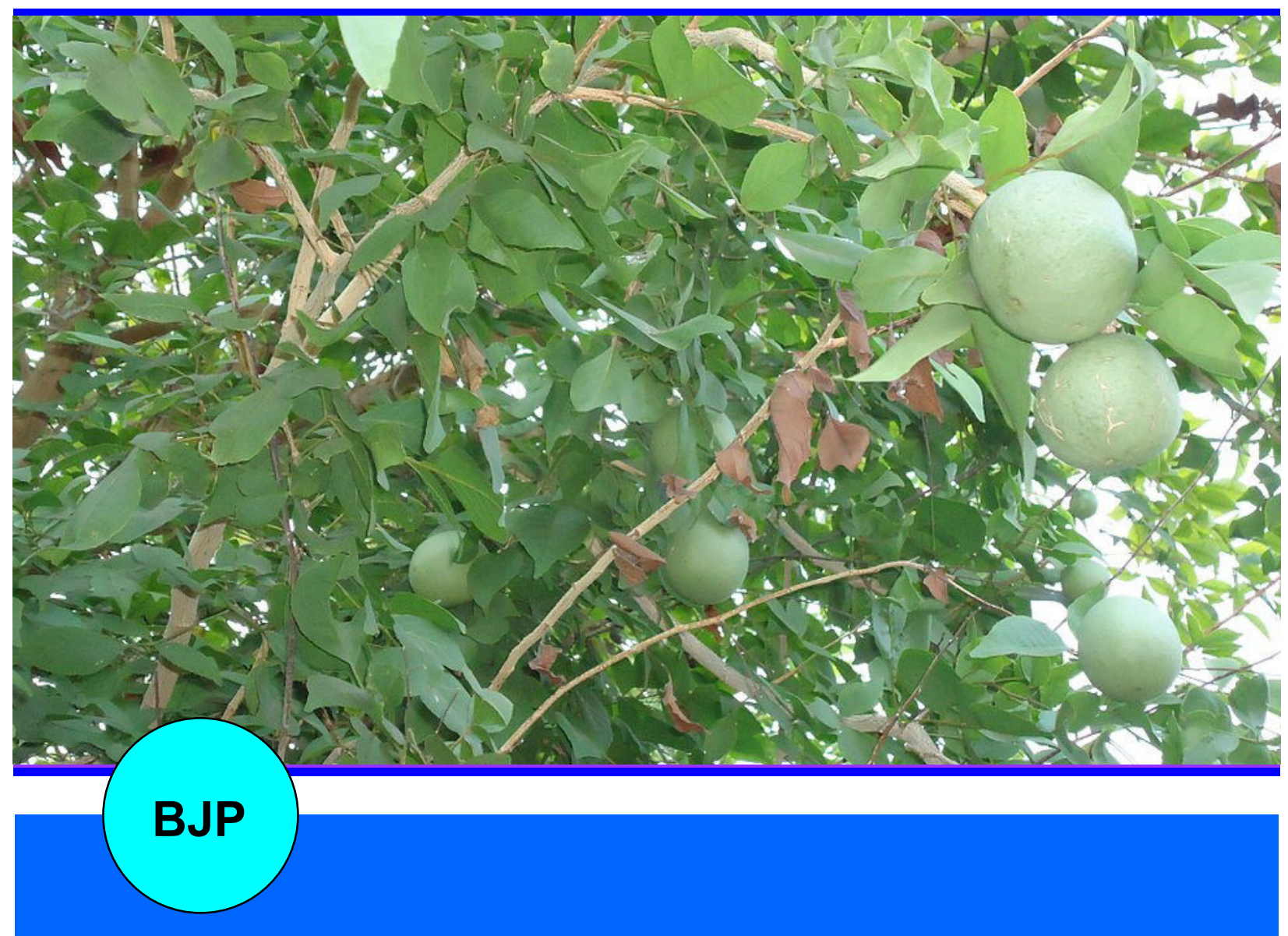

Bangladesh Journal of Pharmacology

Research Article

In vitro glucose uptake by isolated rat hemi-diaphragm study of Aegle marmelos Correa root 
Abstracted/indexed in Academic Search Complete, Asia Journals Online, Bangladesh Journals Online, Biological Abstracts, BIOSIS Previews, CAB Abstracts, Current Abstracts, Directory of Open Access Journals, EMBASE/Excerpta Medica, Global Health, Google Scholar, HINARI (WHO), International Pharmaceutical Abstracts, Open J-gate, Science Citation Index Expanded, SCOPUS and Social Sciences Citation Index

ISSN: $1991-0088$

\title{
In vitro glucose uptake by isolated rat hemi-diaphragm study of Aegle marmelos Correa root
}

\author{
Subban Ravi', C. T. Sadashiva², T. Tamizmani3 ${ }^{3}$ T. Balasubramanian3, M. Rupeshkumar3 \\ and Indira Balachandran²
}

${ }^{1}$ Department of Chemistry, Karpagam University, Coimbatore, Tamilnadu, India; ${ }^{2}$ Phytochemistry Division, Centre for Medicinal Plants Research, Arya Vaidya Sala, Kottakkal 676 503, Kerala, India; ${ }^{3}$ Bharathi college of Pharmacy,

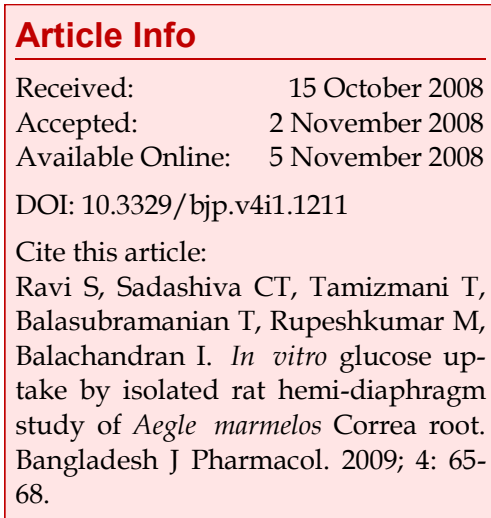

Abstract
The methanol extract of the root of Aegle marmelos, a medicinal plant, was
fractionated into eight fractions using column chromatography. The antidia-
betic activity of all the fractions was studied using the glucose uptake by iso-
lated rat hemi-diaphragm in vitro model. Using the bioassay-guided fractiona-
tion, two compounds 1 and 2 were isolated by column chromatography and
identified as 6-methyl-4-chromanone and skimmianine respectively by NMR
and mass spectral methods.

\section{Introduction}

An increasing number of research papers and reviews clearly indicate that medicinal plants exhibit a variety of therapeutic properties and could provide health security to rural people primary health care. Among medicinal plants Aegle marmelos Correa (family Rutaceae) appears to be relevant and this plant is available in India, Bangladesh, Burma and Sri Lanka. Its distribution is mainly within the sub-Himalayan forests, in dry hilly places ascending to 4,000 feet. It is called "Shivadume", the tree of Shiva. Since ancient time, its leaves are offered to Shiva and Parvathi. A. marmelos has an important place in indigenous systems of medicine. With respect to pharmacology, alcoholic and aqueous extracts of the leaves had similar effects as digoxin in amplitude and contractions of the frog heart and methanolic extracts of roots inhibited the beating rate by approximately $50 \%$ of cultured mouse myocardial cells (Kakiuchi et al., 1991). Alcoholic extracts of the roots and fruits showed hypoglycemic and antidiabetic activity (Kamalakkannan et al., 2003; Karuna-nayake et al., 1984; Sabu and Kuttan, 2004). With respect to clinical applications, it should be noted that the roots are astringent, bitter and febrifuge. They are useful in diarrhea, dysentery, dyspepsia, stomachalgia (Shoba and Thomas, 2001), cardiopalmus, seminal weakness, vomiting, intermittent fever swellings. The leaves of $A$. marmelos are useful as laxative, febrifuge and expectorant, also in ophthalmia, deafness, inflammations, cataract, diabetes, asthmatic and antifungal complaints (Rana et al., 1997). Also, the effect of these extracts was examined in the regulation of hyperthyroidism (Kar et al., 2002) and for the analgesic activity in mice. The stem extract inhibit in vitro proliferation of human tumor cell lines (Lampronti et al., 2003).

Diabetes mellitus is a major disease characterized by derangement in carbohydrate, fat and protein metabolism, affecting nearly $10 \%$ of the population. In the recent past many hypoglycemic agents are introduced, still the diabetes and the related complications continue 
to be a major medical problem not only in developed countries but also in developing countries. Many Indian medicinal plants are reported to be useful in diabetes. However, search for new antidiabetic drugs continue. Although the leaves and fruits of A. marmelos were studied widely for their antidiabetic activity (Narendrakannan et al., 2006; Kesari et al., 2006), the reports on antidiabetic activity of roots are limited. The present study was aimed at investigating the antidiabetic effect of $A$. marmelos and identifying the active principles.

\section{Materials and Methods \\ Plant material}

A. marmelos was collected from Kottakkal, Mallapuram district, Kerala during September 2007 and authenticated at the Botany Division, Centre of Medicinal Plants Research, Arya Vaidya Sala, Kottakkal, Kerala, where the voucher specimen is maintained.

\section{Extraction}

About $20 \mathrm{~g}$ of air-dried root of the A. marmelos was powdered and refluxed with methanol for 8 hours over a water bath. The extract was filtered and concentrated under reduced pressure in a rotary evaporator below $50^{\circ} \mathrm{C}$. The concentrated extract was dissolved in $10 \mathrm{~mL}$ of methanol and used for the gas chromatography analysis.

\section{Fractionation using column chromatography}

The air-dried root (500 g) was ground and extracted exhaustively with methanol $(3 \times 1.0 \mathrm{~L})$ for 48 hours. The extracts were combined and freed of solvent to give $2.7 \mathrm{~g}$ of residue. The residue was subjected to column chromatography on $80 \mathrm{~g}$ of $\mathrm{Si}$ gel and eluted with nhexane $(100 \mathrm{~mL})$ followed with a mixture of $n$-hexane and ethyl acetate containing increasing amounts of ethyl acetate. Finally the column was eluted with pure ethyl acetate. Seventy-eight fractions ( $25 \mathrm{~mL}$ each) were collected and pooled according to their similarity on analytical TLC plates and dried. Combined fractions 1-9 (FA, $165 \mathrm{mg}), 10-21$ (FB, $190 \mathrm{mg}), 22-27$ (FC, $141 \mathrm{mg}), 28$ -35 (FD, $132 \mathrm{mg}$ ), 36-47 (FE, $141 \mathrm{mg}), 48-60$ (FF, $181 \mathrm{mg})$, 61-72 (FG, $156 \mathrm{mg}$ ) and 73-78 (FH, $153 \mathrm{mg}$ ) were obtained.

\section{Isolation of compounds}

The fraction FC (100 mg) was subjected to column chromatography on $20 \mathrm{~g}$ of Si gel G and eluted with a mixture of n-hexane: Ethyl acetate (8:2). Fractions $(5 \mathrm{~mL}$ each) were collected and pooled according to their similarity on analytical TLC plates and dried. Combined fractions 7-10 (1, $21 \mathrm{mg}), 18-22(\mathbf{2}, 10 \mathrm{mg})$ were obtained. They were characterized by NMR and MS spectral data as 6-methyl-4-chromanone and skimmianine respectively.

${ }^{1} \mathrm{H}$ NMR (500 MHz) and ${ }^{13} \mathrm{C}$ NMR (150.9 MHz) spectra were measured on a JEOL JNM LA-500 instrument using acetone- $\mathrm{d}_{6}$ and $\mathrm{CD}_{3} \mathrm{OD}$ solvents. APCI-MS were determined on an Agilent (Palo Alto, CA, USA) MSD 1100 single-quadropole spectrometer.

\section{Compound 1}

APCI- MS (negative mode) m/z 161 [M-H]; NMR: $\delta$ $\left(\mathrm{CDCl}_{3}\right) 2.35$ (3H, s, methyl protons), $3.01(2 \mathrm{H}, \mathrm{d}$ $\left.\mathrm{CH}_{2} \mathrm{CO}\right), 4.21\left(2 \mathrm{H}, \mathrm{d}, \mathrm{OCH}_{2}\right), 6.78(1 \mathrm{H}, \mathrm{d}$, aromatic) and 7.32 (2H, m, aromatic). ${ }^{13} \mathrm{C}-\mathrm{NMR}$ data; $\delta 66.9$ (C-2), 37.8 (C-3), 196.8 (C-4), 129.2 (C-5), 128.7 (C-6), 134.10 (C-7), 114.2 (C-8), 154.2 (C-9) and 123.5 (C-10).

\section{Compound 2}

APCI-MS (positive mode) m/z $260[\mathrm{M}+\mathrm{H}]^{+}$; NMR: $\delta$ $(\mathrm{CDCl} 3) 3.68\left(9 \mathrm{H}, \mathrm{s}, \mathrm{OCH}_{3}\right)$, and aromatic protons at $\delta$ $6.4(1 \mathrm{H}, \mathrm{d}), 7.35(3 \mathrm{H}, \mathrm{m}) .{ }^{13} \mathrm{C}-\mathrm{NMR}$ data; $\delta 149.8(\mathrm{C}-3)$, 141.8 (C-4), 118.3 (C-5), 116.9 (C-6), 154.1 (C-7), 104.2 (C8), 146.2 (C-9) and 163.5 (C-10), 103.4 (C-11), 157.4(C-12) and 140.6 (C-13).

\section{Gas chromatography analysis}

An Agilent 6890N model GC gas chromatograph was used for the analysis. The analysis was performed as described elsewhere (Lampronti et al., 2003).

\section{Animals}

Colony bred, healthy Wister albino rats of either sex weighing 200-220 g were taken for the study. The animals were fed on standard laboratory diet with water ad libitum and housed at room temperature. The rats were kept of fasting overnight with free access to water during the experiment in the same ambience. The animals were divided into four groups of six animals each.

\section{Glucose uptake by isolated rat hemi-diaphragm}

Glucose uptake by rat hemi-diaphragm was estimated by the methods described elsewhere (Walaas and Walaas, 1952; Chattopadhyay et al., 1992) with some modifications. Four sets containing six numbers of graduated test tubes $(n=6)$ for each fraction (Fraction 1 -8) were taken. Group I served as a control which contained $2 \mathrm{~mL}$ of Tyrode solution with $2 \%$ glucose, Group II contained $2 \mathrm{~mL}$ Tyrode solution with 2\% glucose and regular insulin (Nova Nardisk) $0.6 \mathrm{~mL}$ of 0.4 units per $\mathrm{mL}$ solution. Group III contained $2 \mathrm{~mL}$ Tyrode solution with $2 \%$ glucose and $1.4 \mathrm{~mL}$ of $A$. marmelos fraction and the Group IV contained $2 \mathrm{~mL}$ Tyrode solution with $2 \%$ glucose and regular insulin 0.6 $\mathrm{mL}$ of 0.4 units per $\mathrm{ml}$ solution and $1.4 \mathrm{~mL}$ of $A$. marmelos fraction.

The volumes of all the test tubes were made up to $4 \mathrm{~mL}$ 


\begin{tabular}{|c|c|c|}
\hline \multicolumn{3}{|r|}{ Table I } \\
\hline \multicolumn{3}{|c|}{$\begin{array}{c}\text { Effect of } A \text {. marmelos fractions FA-FH using glu- } \\
\text { cose uptake by isolated rat-hemi diaphragm in } \\
\text { vitro assay }\end{array}$} \\
\hline SN. & Group & Glucose uptake (mg/g/30 min) \\
\hline 1 & Control & $5.7 \pm 0.01$ \\
\hline 2 & Insulin & $15.7 \pm 0.2^{b}$ \\
\hline 3 & FA & $20.3 \pm 0.2$ \\
\hline 4 & Insulin + FA & $19.7 \pm 0.2$ \\
\hline 5 & $\mathrm{FB}$ & $30.3 \pm 0.2 c$ \\
\hline 6 & Insulin + FB & $28.8 \pm 0.3$ \\
\hline 7 & $\mathrm{FC}$ & $40.7 \pm 0.2 c$ \\
\hline 8 & Insulin + FC & $30.7 \pm 0.2$ \\
\hline 9 & FD & $6.8 \pm 0.3$ \\
\hline 10 & Insulin + FD & $8.3 \pm 0.2$ \\
\hline 11 & FE & $24.3 \pm 0.2^{c}$ \\
\hline 12 & Insulin + FE & $22.7 \pm 0.2$ \\
\hline 13 & $\mathrm{FF}$ & $22.3 \pm 0.2 c$ \\
\hline 14 & Insulin + FF & $20.3 \pm 0.2$ \\
\hline 15 & FG & $24.3 \pm 0.2 c$ \\
\hline 16 & Insulin + FG & $23.2 \pm 0.2$ \\
\hline 17 & $\mathrm{FH}$ & $21.2 \pm 0.3 c$ \\
\hline 18 & Insulin FH & $20.2 \pm 0.2^{a}$ \\
\hline & $\begin{array}{l}\text { re mean } \pm \text { SEN } \\
\text { the control gro }\end{array}$ & $\begin{array}{l}\text { 6; a } p<0.05, \text { b }<<0.01, c p<0.001 \text { as com- } \\
\text { e-way ANOVA }\end{array}$ \\
\hline
\end{tabular}

with distilled water to match the volume of the test tubes of group IV. Albino rats were tested overnight and killed by decapitation. The diaphragms were dissected out quickly with minimal trauma and divided into two halves. Two diaphragms from the same animal were not used for the same set of experiment. Six numbers of diaphragms were used for each group (Fr 1 -8). The hemi-diaphragms were placed in test tubes and incubated for $30 \mathrm{~min}$ at $37^{\circ} \mathrm{C}$ in an atmosphere of $100 \%$ oxygen with shaking at 140 cycles/min. Glucose uptake per gram of tissue was calculated as the difference between the initial and final glucose content in the incubated medium.

\section{Statistics}

The data were analyzed using one-way ANOVA followed by Dunnett"s test.

\section{Results and Discussion}

The estimation of glucose content in rat hemidiaphragm was employed for in vitro study of peripheral uptake of glucose. The effects of the $A$. marmelos fractions FA-FH on glucose uptake by isolated rat-hemi diaphragm are shown in Table I. The fractions FB and FC enhances the uptake of glucose by isolated rat hemi-diaphragm significantly $(\mathrm{p}<0.001)$ and was found to be more effective than insulin. Administration of $A$. marmelos fractions and insulin together was found to be less effective than $A$. marmelos fractions alone, but significantly higher than insulin treated group $(\mathrm{p}<0.001)$.

The gas chromatography analysis was performed as described in Lampronti et al. (2003). The resulting chromatogram indicated that one intense peak (retention time $19.3 \mathrm{~min}$ ), corresponding to 6-methyl-4chromanone, is present in the extract which matches with the results of Lampronti et al. (2003).

Fractions FB and FC were analyzed with TLC and found that there were two spots in the fractions $\mathrm{FB}$ and FC showing the same Rf value at 0.4 and 0.5 . These two compounds 1 (13 $\mathrm{mg}$ ) and 2 (9 mg) were isolated by column chromatography of the fraction FB on Si gel G and eluted with a mixture of $n$-hexane: Ethyl acetate $(8: 2)$. The structure of the compounds (Figure 1) was elucidated using MS and ${ }^{1} \mathrm{H}-\mathrm{NMR}$ analysis.

Conventional antidiabetic agents can affect several pathways of glucose metabolism such as insulin secretion, glucose uptake by target organs as well as nutrient absorption.

The estimation of glucose content in rat hemidiaphragm is a commonly employed and reliable method for in vitro study of peripheral uptake of glucose.

Among the fractions tested the fractions FB and FC enhances the uptake of glucose by isolated rat hemidiaphragm significantly $(\mathrm{p}<0.001)$ and was found to be more effective than insulin. It appears that fractions FB and FC have direct peripheral action. Administration of A. marmelos fractions and insulin together was found to be less effective than $A$. marmelos fractions alone, but significantly higher than insulin treated group $(\mathrm{p}<$ 0.001). It appears that drug interaction could have occurred between $A$. marmelos fractions and insulin when given together. The control value of the glucose uptake by rat hemi-diaphragm $(5.7 \pm 0.01)$ corresponds with the findings of Chattopadhyay et al. (1992). Gas chromatography analysis indicated the presence of 6methyl-4-chromanone, in the extract which matches with the results of Lampronti et al. (2003).

Compound $\mathbf{1}$ had a molecular formulae $\mathrm{C}_{10} \quad \mathrm{H}_{10} \mathrm{O}_{2}$

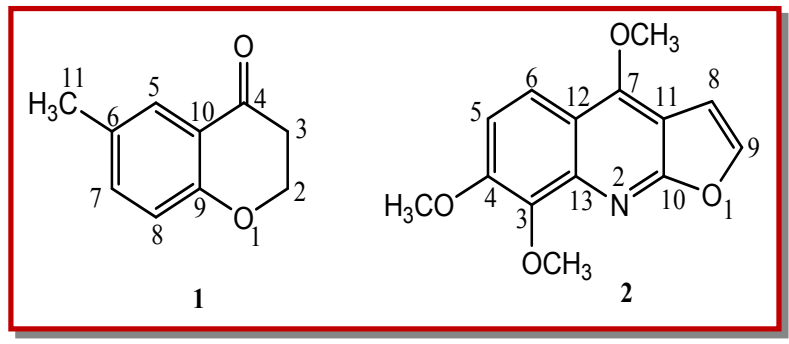

Figure 1: Structures of compounds 1 and 2 
evident from its APCI- MS (negative mode) spectrum by exhibiting a peak at $\mathrm{m} / \mathrm{z} 161[\mathrm{M}-\mathrm{H}]^{-}$. Its NMR spectrum showed peaks at $\delta 2.35(3 \mathrm{H}, \mathrm{s}$, methyl group attached to an aromatic ring), $3.01\left(2 \mathrm{H}, \mathrm{d},-\mathrm{CH}_{2} \mathrm{CO}\right)$, $4.21\left(2 \mathrm{H}, \mathrm{d},-\mathrm{OCH}_{2}\right), 6.78(1 \mathrm{H}, \mathrm{d}$, aromatic) and $7.32(2 \mathrm{H}$, $\mathrm{m}$, aromatic) and identified as 6-methyl-4-chromanone. ${ }^{13} \mathrm{C}-\mathrm{NMR}$ data confirms the structure of $1 ; \delta 66.9$ (C-2), 37.8 (C-3), 196.8 (C-4), 129.2 (C-5), 128.7 (C-6), 134.10 (C7), 114.2 (C-8), 154.2 (C-9) and 123.5 (C-10). Compound 2 had a molecular formulae $\mathrm{C}_{14} \mathrm{H}_{13} \mathrm{O}_{4} \mathrm{~N}$ evident from its APCI-MS (positive mode) spectrum by exhibiting a peak at $\mathrm{m} / \mathrm{z} 260[\mathrm{M}+\mathrm{H}]^{+}$. Its NMR spectrum showed peaks at $\delta 3.68\left(9 \mathrm{H}, \mathrm{s}\right.$, three $\left.-\mathrm{OCH}_{3}\right)$, and aromatic protons at $\delta 6.4(1 \mathrm{H}, \mathrm{d}), 7.35(3 \mathrm{H}, \mathrm{m})$ and the ${ }^{13} \mathrm{C}-\mathrm{NMR}$ data confirms the structure of $\mathbf{2}$ as skimmianine; $\delta$ 149.8 (C-3), 141.8 (C-4), 118.3 (C-5), 116.9 (C-6), 154.1 (C7), 104.2 (C-8), 146.2 (C-9) and 163.5 (C-10), 103.4 (C-11), 157.4(C-12) and 140.6 (C-13). Already skimmianine, was found to have a significant inhibitory effect on spontaneous motor activity, exploratory behavior, cataleptogenic activity, conditioned avoidance response and long-term isolation-induced fighting of animals. A mild antimethamphetamine activity was also observed. Its neuroleptic activity was less potent than that of chlorpromazine (Cheng, 2003), it has inhibitory activity against the enzyme adenine phosphoribosyltransferase (APRT) from Leishmania, a tropical parasite causing endemic disease in poor countries (Napolitano et al., 2008), function as antagonists of 5-hydroxytryptamine receptors in animals (Cheng et al., 1994), and 6-methyl4-chromanone was earlier isolated from stem extract of A. marmelos and found to inhibit the in vitro proliferation of human tumor cell lines, including the leukemic K562, T-lymphoid Jurkat, B-lymphoid Raji, erythroleukemic HEL, melanoma Colo38, and breast cancer MCF7 and MDA-MB-231 cell lines (Lampronti et al., 2003). Our results suggest that 6-methyl-4chromanone $\mathbf{1}$ and skimmianine $\mathbf{2}$ may be responsible for the in vitro antidiabetic effect.

\section{References}

Chattopadhyay RR, Sarkar SK, Ganguly S, Banerjee RN, Basu TK. Effect of leaves of Vinca rosea Linn, on glucose utilization and glycogen deposition by isolated rat hemidiaphragm. Indian J Physiol Pharmacol. 1992; 36: 137-38.
Cheng JT. Effect of skimmianine on animal behavior. Acta Cryst. 2003; E59: 1503-05.

Cheng JT, Chang TK, Chen IS. Skimmianine and related furoquinolines function as antagonists of 5-hydroxy-tryptamine receptors in animals. J Auton Pharmacol. 1994; 14: 365-74.

Kakiuchi N, Senaratne LR, Huang SL, Yang XW, Hattori M, Pilapitiya U, Namba T. Effects of constituents of Beli (Aegle marmelos) on spontaneous beating and calcium paradox of myocardial cells. Plants Med. 1991; 57: 43-46.

Kamalakkannan N, Rajadurai M, Prince PS. Effect of Aegle marmelos fruits on normal and streptozotocin-diabetic Wistar rats. J Med Food. 2003; 6: 93-98.

Kar A, Panda S, Barthi S. Relative efficacy of these medicinal plant extracts in the alteration of thyroid hormone concentration in male mice. J Ethnopharmacol. 2002; 81: 281-85.

Karunanayake EH, Welihinda J, Sirimanne SR, Sinnadorai G. Oral hypoglycemic activity of some medicinal plants of Sri Lanka. J Ethnopharmacol. 1984; 11: 223-31.

Kesari A, Gupta RK, Singh SK, Diwakar S, Watal G. Hypoglycemich and antihyperglycemic activity of A. marmelos seed extract in normal and diabetic rats. J Ethnopharmacol. 2006; 107: 374-79.

Lampronti I, Martello N, Bianchi N, Borgatti M, Lambertini E, Piva R, Jabbar S, Choudhuri MSK, Khan MTH, Gambari R. In vitro anti-proliferative effects on human tumor cell lines of extracts from the Bangladeshi medicinal plant Aegle marmelos Correa. Phytomedicine 2003; 10: 300-08.

Napolitano HB, Silva M, Ellena J, Rocha WC, Vieira PC, Thiemann OH, Oliva G. Redetermination of skimmianine: A new inhibitor against the Leishmania APRT enzyme. Automatic Autacoid Pharmacol. 2008; 14: 365-74.

Narendrakannan RT, Subramanian S, Kandaswamy M. Biochemical evaluation of anti-diabetogenic properties of some commonly used Indian plants on streptozotocin-induced diabetes in experimental rats. Clin Exp Pharmacol Physiol. 2006; 33: 1150-57.

Rana BK, Singh UP, Taneja V. Antifungal activity and kinetics of inhibition by essential oil isolated from leaves of Aegle marmelos. J Ethnopharmacol. 1997; 57: 29-34.

Sabu MC, Kuttan R. Antidiabetic activity of Aegle marmelos and its relationship with its antioxidant properties. Indian J Physiol Pharmacol. 2004; 48: 81-88.

Shoba FG, Thomas M. Study of anti-diarrheal activity of four plants in castor oil-induced diarrhea. J Ethnopharmacol. 2001; 76: 73-76.

\footnotetext{
Author Info

Subban Ravi (Principal contact)

e-mail: ravisubban@rediffmail.com
} 